\title{
Scientific Prediction in the Beginning of the "Historical Turn": Stephen Toulmin and Thomas Kuhn
}

\author{
Wenceslao J. Gonzalez \\ Department of Humanities, University of A Coruña, Spain \\ Email: wencglez@udc.es
}

Received January $14^{\text {th }}, 2013$; revised February $17^{\text {th }}, 2013$; accepted March $2^{\text {nd }}, 2013$

\begin{abstract}
Copyright (C) 2013 Wenceslao J. Gonzalez. This is an open access article distributed under the Creative Commons Attribution License, which permits unrestricted use, distribution, and reproduction in any medium, provided the original work is properly cited.
\end{abstract}

\begin{abstract}
This paper considers the similarities and differences between Toulmin and Kuhn on the problem of prediction. The context of the analysis is the beginning of the "historical turn" in philosophy of science (i.e., the period before the 1965 international colloquium held at Bedford College). The comparison between these authors takes into account several levels: semantic, logical, epistemological, methodological, ontological, and axiological. The main goal is to analyze whether there are influences of Toulmin in Kuhn regarding scientific prediction or, at least, if the former reached similar positions to the latter on the issue of the role of prediction in science.
\end{abstract}

Keywords: Toulmin; Kuhn; Scientific Prediction; Historical Turn; Similarities; Differences

\section{Historical Context}

The "historical turn" in the philosophy and methodology of science is commonly attributed to Thomas Kuhn and Imre Lakatos. In addition, there are contemporary authors, such as Paul Feyerabend, and later thinkers, such as Larry Laudan, who developed a view on philosophy of science based on the contributions of history of science. Before the "historical turn" was well established, some specialists made analyses in favor of this historiographic dimension: on the one hand, is the case of Ludwik Fleck, who passed almost unknown in the mid-thirties; ${ }^{1}$ and, on the other hand, is the case of Norwood Russell Hanson and Stephen Toulmin, who were more influential but did not get the "turn" that Kuhn achieved later on.

\section{Stephen Toulmin and Thomas Kuhn: Some Similarities}

Toulmin has some similarities with the author of The Structure of Scientific Revolutions (Kuhn, [1962b], 1970a). (i) In Philosophy of Science (Toulmin, 1953) and in Foresight and Understanding (Toulmin, 1961) he emphasizes the role of language in science. Toulmin receives the direct influence of Ludwig Wittgenstein, a thinker who also has repercussions in Kuhn's approach (mainly in his pragmatic view of the meaning of scientific terms). (ii) They agree that the structure of scientific theories is no longer a logical structure of the kind accepted by the logical positivists (or even by Karl Popper). (iii) For Toulmin and Kuhn, epistemological factors are not a construction like a building (from foundations on) but rather a dynamic interaction with the social environment or historical context. (iv) Methodologically, both thinkers take into account

\footnotetext{
${ }^{1}$ An interesting comparison between Fleck's views and Kuhn's approach is in Mößner (2011), pp. 362-371.
}

the role of prediction as a guarantee of the validity of scientific knowledge. (v) Ontologically, they see science as a human activity rather than as an abstract amount of impersonal knowledge. (vi) Axiologically, they recognize the importance of the aim of scientific prediction, although they do not consider it from a predictivist approach (like Hans Reichenbach did in 1938 with Experience and Prediction), (cf. Reichenbach, 1938; see Gonzalez, 1995: pp. 35-56).

Within this historic-systematic context, the paper pays attention to the similarities and differences between Toulmin and Kuhn on the problem of prediction. The comparison takes into account the levels pointed out: semantic, logical, epistemological, methodological, ontological, and axiological. The analysis will focus on the beginning of the "historical turn," i.e., the period before the 1965 international colloquium in philosophy of science held at Bedford College. The main goal is to analyze whether there are influences of Toulmin on Kuhn regarding scientific prediction or, at least, if the former reached similar positions to the latter on the issue of the role of prediction in science.

\section{A Comparative Analysis on Prediction: Toulmin and Kuhn}

In 1961 Toulmin emphasized the connection between history of science and philosophy of science. ${ }^{2}$ He wrote: "the critical questions which a philosopher brings to science need to be co-ordinated with the factual studies of history." 3 This was written before Kuhn's historiographic book was published,

\footnotetext{
2 "My debts to the working historians of science are so obvious as not to require detailed acknowledgment,” Toulmin (1961), p. 5

${ }^{3}$ Toulmin (1961), p. 16. "I have aimed (...) at showing the fascinating problems that arise when one brings logical and philosophical questions to bear on the history of our scientific ideas," Foresight and understanding: An inquiry into the aims of science, p. 94.
} 
where he defends a key role for history of science, which leads to the philosophic-methodological categories of "normal science" and "scientific revolution."

\section{Semantics of Prediction}

According to Toulmin, “words like 'prediction' (...) conceal hidden ambiguities” (Toulmin, 1961: p. 16). Moreover, he makes explicit that, in his judgment, "the word 'prediction' is in fact a very slippery one. It slides between two extreme uses: one naive, the other sophisticated. In its most obvious and appealing sense, explaining and predicting are emphatically not all-of-a-piece; but, by hedging the term around with sufficient qualifications, we can at least use it to provide a definition of explanation" (Toulmin, 1961: p. 23).

Initially, following the Wittgensteinian influence - a pragmatic account on language —, Toulmin considers that the terms such as "prediction" or "predictive" can be understood in the familiar, non-philosophical sense. This means that there are "pre-dictions, fore-tellings, sayings-in-advance” (Toulmin, 1961: p. 24). In addition, he does not distinguish between "foresight," "prediction," and "forecasting," which — in my judgment should be done in order to analyze the foretellings in terms of the different degree of control of the variables. This possibility is more relevant in economics than in other sciences (cf. Gonzalez, 1996b: pp. 201-228; especially, pp. 215-216).

But Toulmin embraces de facto another position: prediction as testable implication. This involves "the ability to infer the occurrence of any event in question - whether it has already happened, is happening now, or is going to happen in the future" (Toulmin, 1961: p. 27). Thus, the distinction between "pre-diction" (saying beforehand that something is going to happen) and "retro-diction" (inferring after the event it has happened) is diluted. This seems to me a mistake, insofar as the future is epistemologically and ontologically related to something with a wide range of possibilities, which is far wider and, eventually, more complex — than the past.

On analyzing Toulmin's texts it seems that his semantics of science includes three different uses of predictions: a) future phenomena that are already confirmed, due to some kinds of laws (e.g., eclipses); b) future events not yet confirmed that are themselves still in the future (Toulmin, 1961: p. 26); and c) past things to be discovered (e.g., in paleontology), (cf. Toulmin, 1961: pp. 26-27). Therefore, he offers us a very confused notion of "prediction:” 'predictive success' can "cover inferences about events at any time - past, present, or future - whether we eventually observe the event itself or only its after-effects" (Toulmin, 1961: p. 27).

Kuhn initially uses "prediction" with the common meaning of something said in advance, be the novelty "expected" or "unexpected" (cf. Kuhn, [1962b], 1970a: p. 35). Thus, it is connected to the idea of "anticipation" rather than to looking back: prediction means — in principle — "foreknowledge,"5 which makes a genuine "retrodiction" really hard. But, to a large extent, it is a "contextual meaning:" prediction depends on a content that vies for the allegiance of the scientific community, ${ }^{6}$ within a paradigm that it is historically supported and

\footnotetext{
$\overline{{ }^{4} \text { Cf. Kuhn ([1962b], 1970a), ch. 1, pp. 1-7. "History (...) could produce a }}$ decisive transformation in the image of science by which we are now possessed,” Kuhn ([1962b], 1970a), p. 1.

${ }^{5}$ Cf. Kuhn ([1962a], 1977), pp. 165-177; especially, p. 167.

${ }^{6}$ Cf. Kuhn ([1961a], 1977), pp. 178-224; especially, p. 200.
}

can be changed any time. This is one of the roots of Kuhn's relativism of his initial philosophic-methodological period. ${ }^{7}$

Another semantic distinction in Kuhn, that has epistemological and methodological consequences, is the difference between "quantitative predictions" and "qualitative predictions.” This distinction is reinforced in Postscript-1969, where he gives more relevance to the former than to the latter: "quantitative predictions are preferable to qualitative ones" (Kuhn, 1970b: p. 185). Previously, he has pointed out that quantitative predictions have had a key role in history of science, such as in Newton's success in predicting astronomical observations (cf. Kuhn, [1962b], 1970a: p. 154) or in the acceptance of Einstein's general theory of relativity. ${ }^{8}$

\section{The Structure of Scientific Theories and Prediction}

From a structural point of view, Toulmin considers that scientific theories can have different orientations: "science is certainly not a matter of forecasting alone, since we also have to discover explanatory connections between the happening we predict" (Toulmin, 1961: p. 16). Thus, he criticizes vehemently the predictivist thesis ${ }^{9}$ (i.e., an instrumentalism on prediction), maybe because he held it before Foresight and Understanding. In this book, he rejects that the purpose of an explanatory science is to lead to predictions and that the merits of a scientific theory are in proportion to the correct predictions that it implies (cf. Toulmin, 1961: pp. 22-23).

To begin with, Toulmin considers that explanatory power cannot be defined in terms of forecasts. He highlights that "plenty of powerful theories have led to no categorical, verifiable forecasts whatever. One obvious example is Darwin's theory, explaining the origin of species by reference to variation and natural selection. No scientist has ever used this theory to foretell the coming-into-existence of creatures of a novel species, still less verified his forecasts. Yet many scientists have accepted Darwin's theory as having great explanatory power" (Toulmin, 1961: pp. 24-25).

It seems that, for Toulmin, there is a structural distinction in science between the realm of "explanation" (i.e., explanatory power) and "prediction” (i.e., predictive success), where the former is good enough to have "acceptable science.” In the case of Darwin's ideas, he maintains that "actual forecasting became possible only with the development of modern ecology and genetics, yet men did not wait for this before recognizing the explanatory merits of the theory of natural selection" (Toulmin, 1961: p. 26).

However, for Toulmin, a quite different case could also be possible: a predictive success without an adequate explanatory conception. Historically, "the Babylonians acquired great forecasting-power, but they conspicuously lacked understanding. To discover that events of a certain kind are predictable even to develop effective techniques for forecasting them - is evidently quite different from having an adequate theory about

\footnotetext{
${ }^{7}$ On the different stages of Kuhn's philosophic-methodological approach, cf. Gonzalez (2004a), pp. 15-103.

${ }^{8}$ The equations of Einstein's general theory of relativity have yielded three predictions that can be compared with observation: "the deflection of light in the sun gravitational field, the precession of the perihelion of Mercury, and the red shift of light from distant stars. Only the first two are actually quantitative predictions in the present state of the theory,” Kuhn ([1961a], 1977), p. $188, \mathrm{n}$.

9 "Osiander provides a classic statement of the predictivist thesis," Toulmin (1961), p. 41.
} 
them, through which they can be understood” (Toulmin, 1961: p. 30).

Given his special interest in trying to show the predictivist thesis as mistaken, Toulmin goes very far in his analysis of prediction, because he conceives "scientific prediction" as diluted in the "explanatory power" of a theory or in the task of "making sense of" a phenomenon. Thus, for him, the term "prediction" can mean the same as "explanatory inference" or "prediction" could be a simple "forecast" that is only one test of the explanatory power of a theory (and it is neither a necessary nor a sufficient one), (cf. Toulmin, 1961: p. 35). Toulmin's mistake is in seeing prediction as a pure instrument, a mere application or "technique" without a real content of its own.

Meanwhile Kuhn's structure of scientific theories - mainly in his first philosophical approach — is focused on two well-known categories: "normal science" and "scientific revolution.” In normal science prediction appears within a small class of factual determinations of paradigms: "A part of normal theoretical work, though a small part, consists simply in the use of existing theory to predict factual information of intrinsic value. The manufacture of astronomical ephemerides, the computation of lens characteristics, and the production of radio propagation curves are examples of this sort." ${ }^{10}$ In this regard, the important thing is to increase both the scope and precision of scientific research.

When the analysis moves towards "scientific revolutions" the relation between prediction and "discoveries" (or novelties of fact) appears as well as the nexus between prediction and "inventions" (or novelties of theory), (cf. Kuhn, [1962b], 1970a: p. 52). In the case of discoveries, Kuhn maintains that "the paradigms subscribed to by Roentgen and his contemporaries could not be used to predict X-rays." 11 Thus, a feature of Kuhnian "extraordinary research" is the novelty introduced by the new paradigm that "permits the prediction of phenomena that had been entirely unsuspected while the old one prevailed" (Kuhn, [1962b], 1970a: p. 154).

\section{Epistemology of Prediction}

Epistemologically, prediction is not - for Toulmin - reduced to knowledge about a possible future event. He considers "prediction" as an "assertion about the occurrence of a particular sort of event - whether in the past, present, or future" (Toulmin, 1961: p. 31). In addition, scientific knowledge can be used either in "categorical predictions" ('a total eclipse of Moon will be on ...') or in "hypothetical and conditional predictions" ('if specified conditions are fulfilled, such and such event will happen' or 'a given event happened in the past will occur again if and whenever such and such antecedent conditions hold'), (cf. Toulmin, 1961: p. 31).

This distinction categorical-conditional or hypothetical predictions has methodological consequences, because Toulmin thinks that the method for testing scientific theories depends on the ability to make conditional predictions rather than categorical predictions. He uses the historical case of the Babylonians, where "categorical predictions are relatively unimportant as a test of the explanatory power of a scientific theory, since

\footnotetext{
${ }^{10}$ Kuhn ([1962b], 1970a), p. 30. On the three normal foci for factual scientific investigation, cf. Kuhn ([1962b], 1970a), pp. 25-34.

${ }^{11}$ Kuhn ([1962b], 1970a), p. 58. "Maxwell’s electromagnetic theory had not yet been accepted everywhere, and the particular theory of cathode rays was only one of several current speculations,” Kuhn ([1962b], 1970a), p. 58.
}

we may discover how to forecast by simple trial-and-error, without any understanding of the processes involved" (Toulmin, 1961: p. 32).

Following this view, Toulmin rejects that commonly a scientific theory is to be judged by the categorical forecasts to which it leads. His conception is different: a theory is "to be judged by the number of factual assertions (past, present or future, categorical or hypothetical) which it supports" (Toulmin, 1961: p. 34). He considers that this position can be seen in the example of Newton's theory. Furthermore, he conceives that "support" here means "makes sense of" or "explains," where the important thing is not the empirical success of a prediction but rather the task of offering an intelligible account of the phenomenon.

Although Kuhn uses also Newton's theory as a key case for prediction, it seems that he gives more relevance than Toulmin to empirical success when there is a comparison between Newton's predictions and actual experiments. For Kuhn, the problem of precision is particularly important (Kuhn, [1962b], 1970a: p. 31). Moreover, precision is - in addition to accuracy - a central epistemological topic of The Structure of Scientific Revolutions. ${ }^{12}$ Thus, he defends that "Newton's success in predicting quantitative astronomical observations was probably the single most important reason for his theory's triumph over its more reasonable but uniformly qualitative competitors" (Kuhn, [1962b], 1970a: p. 154).

Nevertheless, when Kuhn analyzes the famous case of paradigm change - the emergence of Copernican astronomy - , he is cautious about "predictive success." He recognizes that the Ptolemaic system "was admirably successful in predicting the changing positions of both stars and planets. No other ancient system had performed so well; for the stars, Ptolemaic astronomy is still widely used today as an engineering approximation; for the planets, Ptolemy's predictions were as good as Copernicus'. But to be admirably successful is never, for a scientific theory, to be completely successful. With respect both to planetary position and to precession of the equinoxes, predictions made with Ptolemy's system never quite conformed with the best available observations” (Kuhn, [1962b], 1970a: p. 68).

Therefore, Kuhn does not endorse here an instrumentalist position. He is not in favor of a predictivist thesis where scientific knowledge should be subordinated to a mere precision or pure accuracy of predictions. He is clear enough when he says that “Copernicus' theory was not more accurate than Ptolemy's and did not lead directly to any improvement in the calendar."13 The difference is in the new "paradigm," because it permits the prediction of new phenomena. But Kuhn goes too far when he links it to "incommensurability," insofar as he holds that, the difference in their predictions (in scientific revolutions), could not occur if the two were logically compatible (cf. Kuhn, [1962b], 1970a: p. 97).

\section{Methodology of Prediction}

Insofar as science has not — for Toulmin — one aim but many, then its development passes through many contrasted stages. Methodologically, he emphasizes several aspects. (i) It is fruitless to seek a single, all-purpose "scientific method,"

\footnotetext{
${ }^{12}$ Cf. Kuhn ([1962b], 1970a), pp. 25-26, 30-31, 36, 42, 52, 153-155, 170, 185 and 199 .

${ }^{13}$ Kuhn ([1962b], 1970a), p. 154. "Until Kepler, the Copernican theory scarcely improved upon the predictions of planetary position made by Ptolemy,” Kuhn ([1962b], 1970a), p. 156.
} 
because science is a human activity that calls for a broad range of different enquires. (ii) There is growth and evolution of scientific ideas that do not depend on a unique method. The diversity of its methods evolves by variation and selection (cf. Toulmin, 1961: p. 17).

Nevertheless, Toulmin sees prediction in instrumental terms: it appears in Foresight and Understanding as a tool or mathematical technique. Due this methodological characteristic, a disconnection is possible in science between explanation (or "understanding") and prediction: "the mathematical techniques used to predict the times and heights of tides, the motions of heavenly bodies, and so on. Yet (as reflection reminds us) some of the most successful techniques for making such predictions have largely lacked the power to explain the events so forecast, having been worked out by trial-and-error and without any theoretical basis; whereas some respectable theories about the very same natural happenings have been predictively almost entirely fruitless” (Toulmin, 1961: p. 27).

Again, this instrumental view leads Toulmin to further confusion: to blur the conceptual distinction between science and technology. He claims that forecasting "is a craft or technology [sic], an application of science rather than the kernel of science itself. If a technique of forecasting is successful, that is one more fact, which scientists must try to explain, and may succeed in explaining. Yet a novel and successful theory may lead to no increase in our forecasting skill; while, alternatively, a successful forecasting-technique may remain for centuries without any scientific basis” (Toulmin, 1961: p. 36).

Methodologically, prediction is in Kuhn connected to the success of a paradigm, (cf. Kuhn, [1962b], 1970a: pp. 23-24). The advancement of science is made "by increasing the extent of the match between those facts and the paradigm's predictions” (Kuhn, [1962b], 1970a: p. 24). Thus, it seems that the Kuhnian success of a paradigm through predictions has similarities with the Lakatosian progress of scientific research programs through prediction of novel facts (cf. Gonzalez, 2001). There are two aspects similar to Lakatos's approach: 1) a genuine scientific advancement is made when predictions lead to novel facts, and 2) anomalies are not a crucial factor for questioning a scientific contribution when predictions are involved.

These aspects - the relevance of prediction of novel facts and the secondary role of anomalies - can be found in Kuhn's texts. a) In some cases, discoveries "like the light spot at the center of the shadow of a circular disk, were predictions from the new hypothesis, ones whose success helped to transform it to a paradigm for later work” (Kuhn, [1962b], 1970a: p. 89). b) A "persistent and recognized anomaly does not always induce crisis. No one seriously questioned Newtonian theory because of the long-recognized discrepancies between predictions from that theory and both the speed of sound and the motion of Mercury.” (Kuhn, [1962b], 1970a: p. 81).

When Kuhn offers his characterization of "The Historical Structure of Scientific Discovery," he distinguishes two main kinds of discoveries: (i) "those discoveries — including oxygen, the electric current, $X$ rays, and the electron - which could be predicted from accepted theory in advance and which therefore caught the assembled profession by surprise” (Kuhn, [1962a], 1977: p. 166), and (ii) those discoveries - the neutrino, radio waves, and the elements which filled empty places in the periodic table - where the existence of the objects "had been predicted from theory before they were discovered, and the men who made the discoveries therefore knew from the start what to look for” (Kuhn, [1962a], 1977: p. 167). This connection between prediction and discovery is used by Kuhn to point out the teleological character of the research in those cases: the foreknowledge provided criteria that told scientists when their goal had been reached (cf. Kuhn, [1962a], 1977: p. 167).

\section{Prediction as a Human Activity (Ontology of Prediction)}

Prima facie, ontology of prediction can be seen in two ways, according to the focus of the analysis: on the one hand, the phenomena that are predicted (as we know, for Toulmin, they could be past, present or future); and, on the other hand, the process itself of predicting, which involves a characterization of science as a whole. In this regard, due to a Wittgensteinian influence, ${ }^{14}$ Toulmin sees science as a human activity rather than an abstract or timeless content, and conceives it as a multi-purpose activity (cf. Toulmin, 1961: p. 18). Moreover, he thinks that the entire range of its activities cannot be encompassed in a single phrase.

Ontologically, prediction as scientific process appears in the context of a human practice. For Toulmin, prediction is based on a "craft" that began on a purely empirical basis, by trial and error, and this happened before its success could be accounted for scientifically. Thus, he distinguishes "scientific predictions and techniques from pre-scientific forecasts and crafts. Any craft may simply be successful as a matter of experience; or alternatively, its efficacy may be intelligible in terms of our general ideas about Nature.” (Toulmin, 1961: p. 37). This means that he is not paying real attention to social sciences.

Even though Toulmin emphasizes the importance of history of science and the difference between the historical periods, his philosophy of science highlights the internal factors of scientific activity. For him, the central aims of science lie in the field of intellectual creation. Thus, other activities — such as predicting - "are properly called 'scientific' from their connection with the explanatory ideas and ideals which are the heart of natural science” (Toulmin, 1961: p. 38). In this regard, a few years later, Toulmin criticizes Kuhn's views on the distinction between normal and revolutionary science. He wants to emphasize that "any attempt to understand the nature of intellectual development in science must, surely, be to distinguish between the intellectual authority of an established conceptual scheme and the magisterial authority of a dominant individual."15

Both normal science and scientific revolutions are, for Kuhn, “community-based activities” (Kuhn, 1970b: p. 179). Among these activities is predicting. This activity has — for him - a particular interest, insofar as the possible knowledge and foreknowledge has more weight than the knowledge that we actually possess, (cf. Kuhn, [1962b], 1970a: p. 171). In this regard, paradigm predictions contribute to the world-view. They have more relevance in scientific revolutions than in normal science, because "no part of the aim of normal science is to call forth new sorts of phenomena” (Kuhn, [1962b], 1970a: p. 24).

Predictive success as such is not, for Kuhn, the main aim of scientific activity of predicting. Thus, he is against an instrumentalist vision of prediction: "to be admirably successful is never, for a scientific theory, to be completely successful"

\footnotetext{
${ }^{14}$ On Wittgenstein’s views on science and prediction, cf. Gonzalez (1996a),

pp. 299-332.
${ }^{15}$ Toulmin (1970), p. 40. This paper was originally delivered in 1965.
} 
(Kuhn, [1962b], 1970a: p. 68). What matters, for him, is that predictions made could be conformed with the best available observations (cf. Kuhn, [1962b], 1970a: p. 68). This seems a realistic element in Kuhnian analysis, where scientific prediction is not a mere "technique." The world-view can be more precise through prediction and, in addition, scientific prediction can enlarge our vision of the world when the new paradigm leads to phenomena that did not appear in old paradigms (cf. Kuhn, [1962b], 1970a: p. 154).

\section{Axiology of Research and Prediction}

For Toulmin, it is clear that science has performed manifold functions. It performs now and might perform in future, within the whole intellectual economy (cf. Toulmin, 1961: p. 15). Thus, he criticizes the attempts made by philosophers to offer characterizations of science where one requirement, such as predictive success, appears as the unique test of a scientific hypothesis. He rejects this possibility: “one cannot hope to get any real understanding from such a nutshell answer. There is no universal recipe for all science and all scientists" (Toulmin, 1961: p. 15). This pluralism about aims involves a diversity of values.

Within the historical context of the beginning of the 1960's, Toulmin offers a quite different approach from the logical empiricist (and, especially, distant from Reichenbach's predictivism) and also diverse from Popper's conception (insofar as he is very critical with the role of "prediction" in science). ${ }^{16}$ But Toulmin does share with them the primacy of internal aims of science over the external elements (social, cultural, etc.). For him, "the central aims of science (...) lie in the field of intellectual creation” (Toulmin, 1961: p. 38). They are "concerned with a search for understanding - a desire to make the course of Nature not just predictable but intelligible — and this has meant looking for rational patterns of connections in terms of which we can make sense of the flux of events" (Toulmin, 1961: p. 99). Thus, for him, "prediction is all very well; but we must make sense of what we predict” (Toulmin, 1961: p. 115).

Even in Kuhn, internal values (epistemological, methodological, etc.) are more important in scientific activity than external values (social, cultural, etc.). Moreover, a few years after his famous book, in Postscript-1969 he emphasized the axiology of research based on prediction when he wrote: "probably the most deeply held values concern predictions: they should be accurate; quantitative predictions are preferable to qualitative ones; whatever the margin of permissible error, it should be consistently satisfied in a given field; and so on” (Kuhn, 1970b: p. 185).

Regarding the values themselves in scientific predictions, Kuhn highlights the increase of scope and precision of research (cf. Kuhn, [1962b], 1970a: p. 30). But there is not — for him - a central value such as "truth" or an ultimate goal of scientific activity. He rejects the idea of science as a process of evolution toward anything. Thus, he claims "if we can learn to substitute evolution-from-what-we-do-know for evolution-toward-what-we-wish-to-know, a number of vexing problems may vanish in the process" (Kuhn, [1962b], 1970a: p. 171). Therefore, for Kuhn, prediction — as well as any other scientific value - is not an objective value, insofar as in The Struc-

\footnotetext{
${ }^{16}$ Popper insists on the role of prediction within the general philosophy and methodology of science, where he is very critical with prediction in the realm of social sciences. Cf. Gonzalez (2004b), pp. 78-98.
}

ture of Scientific Revolutions the possibility of an objective account of nature or a process that can bring us closer to an ultimate goal such as truth is dismissed (cf. Kuhn, [1962b], 1970a: p. 171).

\section{Final Remarks}

From the comparison between Toulmin and Kuhn on prediction, it seems that the differences are more intense than the similitudes. (i) Semantically, prediction has in Toulmin a more vague and polysemous meaning than in Kuhn. This happens as a consequence of the sense of prediction as a "testable implication" whose reference could be in the past, present or future; whereas the Kuhnian approach connects the use of "prediction" with anticipation of an event that, at least for the scientific community, has a novelty and appears as a possible future event.

(ii) Logically, the focus in the structure of scientific theories is also diverse in both authors. Toulmin insists on the relation between prediction and the traditional topics of explanation (and "understanding") of a scientific theory, whereas Kuhn deals with prediction within his distinction "normal science""scientific revolution," which involves "paradigms" rather than individual scientific theories that are seen from a linguistic perspective.

(iii) Epistemologically, both thinkers are keen on evolutionary ideas, ${ }^{17}$ but scientific knowledge of prediction is considered from two different angles: on the one hand, there is a particular interest in Toulmin to discredit any predictivist approach on prediction (statements that could be about past, present or future events); and, on the other hand, there is a notorious emphasis in Kuhn on prediction as a key contribution to scientific knowledge.

(iv) From a methodological point of view, both philosophers of science shared that there is not a single, all-purpose "scientific method,” because they see science as a human activity open to a broad range of different enquires. The difference is in Kuhn's insistence on prediction as connected to genuine novelty (i.e., future rather than past or present) and that prediction can lead to discoveries. To some extent, his views connect to Lakatos's perspective on prediction and novel facts based on historical cases of science.

(v) Ontologically, the scientific activity of predicting is to some extent different in Toulmin and Kuhn. For the former, prediction is an impersonal "craft" or "technique" (cf. Toulmin, 1961: p. 36); meanwhile, for the latter, prediction is developed by the scientific community towards precision and accuracy. The technique is an instrument to be inserted in an explanatory context in order to "make sense" of the world, whereas the Kuhnian emphasis on precision and accuracy, which highlights quantitative predictions over qualitative ones, looks for a genuine information on the world that has weight on its own.

(vi) Axiologically, prediction has a clearer value in Kuhn than in Toulmin. But, due to the general approach of the philosophic-methodological period of The Structure of Scientific Revolutions, prediction appears as a value of a relativistic framework. Toulmin does not go so far. His instrumentalism is open to the value of truth: "science progresses, not by recog-

\footnotetext{
${ }^{17}$ Evolutionary Epistemology — or at least a Darwinian influence on scientific knowledge - is in both authors. "In the evolution of scientific ideas, as in the evolution of species, change results from the selective perpetuation of variants,” Toulmin (1961), p. 110. Cf. Kuhn ([1962b], 1970a), pp. 170-172.
} 
nizing the truth of new observations alone, but making sense of them” (Toulmin, 1961: p. 81).

\section{REFERENCES}

Andersen, H., Barker, P. and Chen, X. (2006). The cognitive structure of scientific revolutions. Cambridge: Cambridge University Press. doi:10.1017/CBO9780511498404

Bird, A. (2005). Naturalizing Kuhn. Proceedings of the Aristotelian Society, 105, 99-117. doi:10.1111/j.0066-7373.2004.00104.x

Goldberg, N. (2011). Interpreting Thomas Kuhn as a response-dependence theorist. International Journal of Philosophical Studies, 19, 729-752. doi:10.1080/09672559.2011.629369

Gonzalez, W. J. (1995). Reichenbach's concept of prediction. International Studies in the Philosophy of Science, 9, 35-56. doi:10.1080/02698599508573505

Gonzalez, W. J. (1996a). Prediction and mathematics: The Wittgensteinian approach. In G. Munevar (Ed.), Spanish studies in the philosophy of science (pp. 299-332). Dordrecht: Kluwer. doi:10.1007/978-94-009-0305-0_15

Gonzalez, W. J. (1996b). On the theoretical basis of prediction in economics. Journal of Social Philosophy, 27, 201-228. doi:10.1111/j.1467-9833.1996.tb00261.x

Gonzalez, W. J. (2001). Lakatos's approach on prediction and novel facts. Theoria, 16, 499-518.

Gonzalez, W. J. (2004a). Las revoluciones científicas y la evolución de Thomas S. Kuhn. In W. J. Gonzalez (Ed.), Análisis de Thomas Kuhn: Las revoluciones científicas (pp. 15-103). Madrid: Trotta.

Gonzalez, W. J. (2004b). The many faces of Popper's methodological approach to prediction. In Ph. Catton and G. Macdonald (Eds.), Karl Popper: Critical appraisals (pp. 78-98). London: Routledge.

Kuhn, Th. S. and Vleck, J. L. van (1950a). A simplified method of computing the cohesive energies of monovalent metals. Physical Review, 79, 382-388. doi:10.1103/PhysRev.79.382

Kuhn, Th. S. (1950b). An application of the W. K. B. method to the cohesive energy of monovalent metals. Physical Review, 79, 515-519.

doi:10.1103/PhysRev.79.515

Kuhn, Th. S. (1951a). A convenient general solution of the confluent hypergeometric equation, analytic and numerical development. Quarterly of Applied Mathematics, 9, 1-16.

Kuhn, Th. S. (1951b). Newton's '31st Query' and the degradation of gold. Isis, 42, 296-298. doi:10.1086/349349

Kuhn, Th. S. (1952a). Robert Boyle and structural chemistry in the seventeenth century. Isis, 43, 12-36. doi:10.1086/349360

Kuhn, Th. S. (1952b). The independence of density and pore-size in Newton's theory of matter. Isis, 43, 364-365. doi:10.1086/348161

Kuhn, Th. S. (1955a). Carnot's version of 'Carnot's Cycle'. American Journal of Physics, 23, 91-95. doi:10.1119/1.1933907

Kuhn, Th. S. (1955b). Le Mer's version of 'Carnot's Cycle'. American Journal of Physics, 23, 387-389. doi:10.1119/1.1934015

Kuhn, Th. S. (1957). The Copernican revolution. Planetary astronomy in the development of western thought. Cambridge: Harvard University Press.

Kuhn, Th. S. (1958). Newton optical papers. In I. B. Cohen (Ed.), Isaac Newton's papers and letters on natural philosophy, and related documents (pp. 27-45). Cambridge, MA: Harvard University Press.

Kuhn, Th. S. (1959a). Energy conservation as an example of simultaneous discovery. In M. Clagett (Ed.), Critical problems in the history of science (pp. 321-356). Madison: University of Wisconsin Press. (Proceedings of the Institute for the History of Science at the University of Wisconsin, September 1-11, 1957); reprinted in Th. S. Kuhn, The essential tension (pp. 66-104).

Kuhn, Th. S. (1959b). The essential tension: Tradition and innovation in scientific research. In C. W. Taylor (Ed.), The third University of Utah conference on the identification of creative scientific talent, (pp. 162-174). Salt Lake City: University of Utah Press, (Conference in Alta, 11-14 June 1959); reprinted in C. W. Taylor and F. Barron (Eds.) (1963), Scientific creativity: Its recognition and development (pp. 341-354). N. York: John Wiley and Sons; reprinted in Th. S. Kuhn, The essential tension (pp. 225-239)

Kuhn, Th. S. (1960). Engineering precedent for the work of Sadi Carnot. Archives Internationales d'Histoire des Sciences, 13, 251-255.

Kuhn, Th. S. ([1961a], 1977). The function of measurement in modern physical science. Isis, 52, 161-193 (paper presented in a Conference of the Social Science Research Council, 20-21 November 1959); reprinted in Th. S Kuhn (1977), The essential tension. Selected studies in scientific tradition and change (pp. 178-224). Chicago: The University of Chicago Press.

Kuhn, Th. S. (1961b). Sadi Carnot and the Cagnard engine. Isis, 52, 567-574. doi:10.1086/349501

Kuhn, Th. S. ([1962a], 1977). The historical structure of scientific discovery. Science, 136, 760-764 (based on a paper read in the joint session of American Historical Association and History of Science Society, 29 December 1961). Reprinted in Th. S. Kuhn (1977), The essential tension. Selected studies in scientific tradition and change (pp. 165-177). Chicago: The University of Chicago Press.

Kuhn, Th. S. ([1962b], 1970a). The structure of scientific revolutions. International Encyclopedia of Unified Science: Foundations of the Unity of Science, v. 2, n. 2. Chicago: The University of Chicago Press. (2nd ed., 1970).

Kuhn, Th. S. (1963a). The function of dogma in scientific research. In A. C. Crombie (Ed.), Scientific change: Historical studies in the intellectual, social and technical conditions for scientific discovery and technical invention, from antiquity to the present (pp. 347-369). London: Heinemann; N. York: Basic Books (symposium on History of Science, Oxford University, 9-15 July 1961).

Kuhn, Th. S. (1963b). Discussion on 'The function of dogma in scientific research'. In A. C. Crombie (Ed.), Scientific change: Historical studies in the intellectual, social and technical conditions for scientific discovery and technical invention, from antiquity to the present (pp. 386-395). London: Heinemann; N. York: Basic Books (symposium on History of Science, Oxford University, 9-15 July 1961).

Kuhn, Th. S. (1964). A function for thought experiments. In I. B. Cohen and R. Taton (Eds.), Mélanges Alexandre Koyré, v. 2: L'aventure de la science (pp. 307-334). Paris: Hermann; reprinted in Th. S. Kuhn (1981). The essential tension (pp. 240-265), and included in I. Hacking (Ed.) (1981), Scientific Revolutions (pp. 6-27). Oxford: Oxford University Press.

Kuhn, Th. S. (1970b). Postscript-1969. In Th. S. Kuhn, The structure of scientific revolutions (pp. 174-210). Chicago, IL: The University of Chicago Press. (2nd ed., 1970)

Kuhn, Th. S. (1977). The essential tension. Selected studies in scientific tradition and change. Chicago, IL: The University of Chicago Press.

Lakatos, I. (1976). Understanding Toulmin. Minerva, 14, 126-143. Reprinted in I. Lakatos, Mathematics, science and epistemology (pp. 224-243), edited by J. Worrall and G. Currie (1978). Cambridge: Cambridge University Press.

Mößner, N. (2011). Thought styles and paradigms - A comparative study of Ludwik Fleck and Thomas S. Kuhn. Studies in History and Philosophy of Science, 42, 362-371. doi:10.1016/j.shpsa.2010.12.002

Nickles, Th. (Ed.) (2003). Thomas Kuhn. Cambridge: Cambridge University Press.

Reichenbach, H. (1938). Experience and prediction. Chicago, IL: The University of Chicago Press.

Sankey, H. (2012). Kuhn, normativity and history and philosophy of science. Epistemologia, 35, 103-111.

Toulmin, S. E. (1950). Probability. Proceedings of the Aristotelian Society, 24, 27-62.

Toulmin, S. E. (1953). The philosophy of science. An introduction. London: Hutchinson University Library. (Third impression, 1957).

Toulmin, S. E. (1959). Criticism in the history of science: Newton on absolute space, time and motion. Philosophical Review, 68, 1-29, and 203-227.

Toulmin, S. E. (1961). Foresight and understanding: An inquiry into the aims of science. Bloomington: Indiana University Press/London: Hutchinson, with a Foreword by Jacques Barzun.

Toulmin, S. E. and Goodfield, J. (1962). The architecture of matter. 
New York: Harper and Row.

Toulmin, S. E. and Goodfield, J. (1965). The discovery of time. New York: Harper and Row.

Toulmin, S. E. (1967). Conceptual revolutions in science. Synthese, 17, 75-91. doi:10.1007/BF00485018

Toulmin, S. E. (1970a). Does the distinction between normal and revolutionary science hold water? In I. Lakatos and A. Musgrave (Eds.), Criticism and the growth of knowledge (pp. 39-47). Cambridge: Cambridge University Press.

Toulmin, S. E. (Ed.) (1970b). Physical reality: Philosophical essays on twentieth-century physics. New York: Harper and Row.

Toulmin, S. E. (1971). From logical systems to conceptual populations. In R. C. Buck and R. S. Cohen (Eds.), In memory of R. Carnap (pp. 552-564). Dordrecht: Reidel.

Toulmin, S. E. (1972). Human understanding, vol. 1. The collective use and evolution of concepts. Oxford: Oxford University Press.

Toulmin, S. E. (1974a). Rationality and scientific discovery. In K. F. Schaffner and R. S. Cohen (Eds.), Proceedings of the 1972 biennal meeting, Philosophy of Science Association (pp. 387-406). Dordrecht: Reidel.
Toulmin, S. E. (1974b). The structure of scientific theories. In F. Suppe (Ed.), The structure of scientific theories (pp. 600-614). Urbana: University of Illinois Press. (2nd ed., 1977).

Toulmin, S. E. (1976). History, praxis and the 'third world'. Ambiguities in Lakatos' theory of methodology. In R. S. Cohen, P. K. Feyerabend and M. W. Wartofsky (Eds.), Essays in memory of Imre Lakatos (pp. 655-676). Dordrecht: Reidel. doi:10.1007/978-94-010-1451-9 36

Toulmin, S. E. (1977). From form to function: Philosophy and history of science in the 1950's and now. Daedalus, 106, 143-162.

Toulmin, S. E. (1981). Teleology in contemporary science and philosophy. Neue Hefte für Philosophie, 20, 140-152.

Toulmin, S. E. (1982). The return to cosmology. Postmodern science and the theology of nature. Berkeley, CA: University of California Press.

Wray, K. B. (2011). Kuhn and the discovery of paradigms. Philosophy of the Social Sciences, 41, 380-397. doi:10.1177/0048393109359778 